\title{
The New Fringe Dwellers: The Problem of Ethnicity in Recent Australian Children's Picture Books
}

\author{
Jeri Kroll
}

\begin{abstract}
ustralian children's books since the 1970 s have usually presented the ethnicity of non-Anglo protagonists as a condition that sets them apart, making them direct their energies towards adapting to a strange land. This paper examines whether writers of recent Australian picture books have been able to move ethnic groups beyond the immigration experience in literature so that the ethnicity of non-Anglo characters is no longer the focus.
\end{abstract}

Before examining a selection of texts published in the 1990s, this paper first discusses what is meant by ethnic characters and then moves to clarify the cultural norm against which these characters are pitted. It also investigates the significance of landscape in defining nationality. Finally, it considers whether having more authors and illustrators of non-Anglo origins working in the field would alter the representation of ethnic groups.

Defining Multicultural Literature

When speaking of literary characters as ethnic, we usually understand the term to refer to "members of the community who are migrants or the descendants of migrants and whose native language is not English'(Macquarie Dictionary 1981, p.614). I am a migrant, for instance, but I have only ever been considered ethnic because my grandparents were Russian Jews, not because I am from another country. The English, as founders of our system of government, provide the norms. Even being born in Australia, then, does not automatically exempt a child from being an 'ethnic'.

Government multicultural policy would have us believe that as a community our goal is to respect 'cultural identity-the right of all Australians ... to express and share their individual cultural heritage, including their language and religion' (Jupp 1996, p.9). But expressing and sharing only go so far - sometimes not even as far as an Anglo child wanting to taste the unfamiliar food in someone else's lunch box. Minorities are always pressured to conform: 'The extent of that conformity is at the heart of all debates about multiculturalism in Australia and elsewhere' (Jupp 1996, p. 18)

How did the organisers of the Australian Multicultural Children's Literature Award view the situation? In a perceptive article in Viewpoint: On Books for Young Adults, Ruth Starke investigates the Award guidelines and finds them problematic: 'According to Meredith Austin of the Office of Multicultural Affairs, which administers the awards, the judges look for a "very naturalistic inclusion, sometimes only in the illustrations $\ldots$ of the children from mixed ethnic backgrounds, all participating on an equal footing"' (Starke 1995, p.22). This inclusion, then, could be minimal. The illustrations could even pander to stereotypes. The token Asian or black child added to a schoolyard scene would not appreciably change the story or put that child in the forefront of the action. Whether Aboriginal and Torres Strait Islander people should be included as those of 'mixed ethnic backgrounds' complicates the picture, too. In fact books either by or about these groups have been considered for or won the Australian Multicultural Children's Literature Awards, but this paper is not the place to discuss whether they should be described as multicultural. The issues involved are far too complex. Suffice it to say that it is the North and South Americans. British, Europeans and Asians who are recent migrants to Australia, not the indigenous population, so Aboriginal and Torres Strait Islander people do not relate to this paper's consideration of the immigration experience.

Certainly a large proportion of Australian educators, politicians, authors and illustrators seek to offer the nation's children of all backgrounds equitable representation in literature. As Senator Nick Bolkus said at the presentation of the Australian Multicultural Children's Literature Awards in 1993:

We all know that what children read stays with them for life. Books help shape their views of themselves and the world they live in. Books form opinions and attitudes, and books have a major influence on children's relationships with each other and society. Soldo not think it is overstating the case to suggest that children's literature today is at the cutting edge of Australia's development as a multicultural society into the 21st century:

(cited in Rawlins 1994, p.243)

Before we move to examine some recent picture books to 
see to what degree equitable representation of cultural identities has been achieved, I want to raise the question of the norm against which the ethnic population is set. Are we clear about what it means to be an Australian. rather than an ethnic, child, living in an identifiably Australian environment?

My Place: What is an Australian landscape?

Defining what it means to be an Australian child and how Australian children relate to their landscape would take a book, let alone another paper. I will only canvass some opinions from those working in the field of children's literature, as critics or as artists, and glance at how the norm has been represented in picture books already.

Australiana can be dispensed with easily enough. Maurice Saxby has already catalogued the market-driven proliferation of books characterised by 'the excessive use of local symbols' (Saxby 1993, p.22). Not only are Australian animals in evidence, but broad slang, tall tales and larrikin humour. This parody of Australianness can be ignored as unrealistic. What about the Australian landscape in general then?

John Stephens believes that landscape is a crucial element in how we analyse children's literature. He insists that 'the aspect of text which most sharply distinguishes the literature of one country from another is sense of place' (Gray 1986, p.5), an observation which can be readily extended to include the depiction of setting in picture books' (Stephens 1994, p.69). Stephens further asserts that 'conventions of illustration' possess their own agenda and so, consciously or unconsciously, 'communicate particular ideas about social organisation and social meaning ...'(1994, p.69). The pictures of our country those ideas purvey is essentially conservative, because they highlight the predominantly nineteenth-century architecture in towns and cities that harks back to a past way of life (Stephens 1994, p.70).

Nadia Wheatley's and Donna Rawlins' My Place (1987), a watershed in the contemporary picture book that must be acknowledged in any discussion of how Australia's children are depicted, utilises landscape in a way that undermines Stephens' argument. The children in $M y$ Place come from distinct cultures, but learn to adapt, too.
On the surface, no one culture dominates - appears superior - in this book. Only its chronological strategy, which moves the reader back in time to the era when Aboriginal people 'belonged' to the land, undisturbed by migration, gives weight to their claims to a special relationship with this place. Through text and picture. therefore, My Place suggests that we revise our conception of ownership, our relationship to the landscape and what it means to be Australian. Wheatley's and Rawlins' innovative treatment of theme and techniques, however. have not been replicated or surpassed as yet.

Can we have, though, a sense of Australianness without landscape? Recently publishers have felt the pressure to market books overseas to ensure financial success and writers are well aware of this agenda. Many firms, especially those producing educational series, prefer non-specific suburban or urban locales. This does not mean that writers or readers have wanted a romanticised version of the bush - they realise that it fails to identify us as contemporary Australians. Indeed, many portrayals of rural life in picture books that are not unrealistic are no longer relevant. Consider the Adelaide Plains' setting of Max Fatchen's nostalgic poem, A Country Christmas (Adelaide: Omnibus, 1990). Timothy Ides' illustrations depict a vanished world. So the connection between landscape in picture books and identity has become fluid it seems. Does the falsity of past stereotypes, however, mean that we cannot rediscover and reclaim the country in which we live?

Illustrator Donna Rawlins does not seem to believe that you can ignore the challenge. She argues that children of diverse ethnic backgrounds have a need and a right to be able to recognise themselves in their own surroundings, whatever they might be:

I live in an archetypal inner city suburb. For many, many Australian children, myenvironment is a carbon copy of their own. Trees: not enough of them. Birds: not enough of them either. And people, people... All these people, from so many countries. Speaking so many languages. settled here, but sometimes homesick for so many distant places

(1994, p.242). 
For Rawlins, people as much as the physical landscape comprise the environment. Why, then, has an altered landscape not appeared in many books to date? Do Anglo children all live on one block and 'the others' live elsewhere, Rawlins asks pointedly? She insists that she is not advocating either propaganda or tokenism: 'That's not to say they [books] necessarily should be about it,' [about cultural landscape] "like so much ideologically correct propaganda, as just to say that they should be books that don't tell fibs, either verbal or visual' (1994, p.247). How successful have recent picture books been in showing children a contemporary Australian landscape where those of ethnic origins feel at home, and where their ethnicity has ceased to be perceived as a problem?

\section{Patterns of Ethnic Difference}

The following examples from the 1990 s will demonstrate that recent picture book texts have succeeded in including more non-Anglo characters, yet in all but two cases, ethnicity is still the primary focus - a condition that interferes with the characters' abilities to feel settled or accepted. I have selected eight trade books published in the past five years, some of which were shortlisted for or won the Australian Multicultural Children's Literature Award for picture books. The examples treat the issue of cultural and ethnic diversity with varying degrees of complexity.

Gillian Rubinstein's Mr Plunkett's Pool (1992), winner of the 1993 Australian Multicultural Children's Literature Award for picture books, still stands as a benchmark for the unobtrusive treatment of our multicultural society. It manages to be humorous, well-written as well as politically correct, although it was not shortlisted by the Children's Book Council of Australia. Mr Plunkett's Pool did win the Multicultural Award, however, to Rubinstein's surprise. In other words, she did not write it in an attempt to jump on the multicultural bandwagon. When I spoke to her about this book soon after it was published, she revealed that to some extent she was only mirroring the cultural diversity in her children's primary school. She wanted her text and the illustrations, which she discussed with Terry Denton, to do what Donna Rawlins has suggested above: to be true verbally and visually to Australian society.
First of all, the twins who are the central characters, Kim and Lee, are not described as Asian. Only their names and obviously their appearance suggest this, something Rubinstein intended. The making visible of this ethnic group, redressing the balance, as it were, is what attracted the notice of the judges of the Multicultural Award: the 'naturalistic inclusion ... of the children from mixed ethnic backgrounds' (Starke 1995, p.22) mentioned earlier. Yet Mr Plunkett's Pool does not only mirror a multicultural society, but an urban population with diverse lifestyles. The twins' Asian identity has no more bearing on the story than the ethnic origins of Despina, Alex or old Mrs Castlemaine. A single, childless couple lives near an extended family, an elderly woman and a single parent. Here is an inner city suburb ripe for renovation, as the story makes apparent.

The only other allusion to the nation as one unified society made up of disparate groups comes in the third to last double-page spread. Mr Plunkett's pool is constructed in the shape of Australia; even Tasmania is included next to the pool as a miniature fountain with a fish spouting water. Rubinstein said that this was Denton's imaginative touch; she had not thought of it. Mr Plunkett had obviously not thought of it either, but he learns from the twins, Kim and Lee.

John Stephens interprets Mr Plunkett's Pool in a radically. different way. He sees the book's setting as offering 'a self conscious contrast between the celebration of one order - the olden days - and the actual emergence of another - modern and postmodern capitalism. the grounding of all social relationships on economics rather than on kinship and community" (1994, p.73). Mr Plunkett only passes on his values to the children, who make a success in advertising and so can build their own pool. Why does Stephens seem to ignore, though, the fact that $\mathrm{Kim}$ and Lee invite the whole street to swim in it, including Mr Plunkett? That inclusiveness points to a new kind of urban harmony. Stephens asserts that the multicultural street can be viewed as 'purely an aspect of social setting and, presumably, of a kind of social propaganda, since none of it has any bearing on the story that is developed' (1994, pp.75-76). But why should it need to be more? Cannot the setting be a reflection of the social reality and so natural, instead of self-conscious? 
The street in Mr Plunkett's Pool suggests that the urban mainstream now looks like Terry Denton's illustration.

Mr Plunkett's Pool, then, succeeds in introducing nonAnglo protagonists whose ethnicity is not the focal point. $\mathrm{Kim}$ and Lee are not token Asian children on the margins of the action; in fact they initiate it. Furthermore, they inhabit a recognisable contemporary urban landscape.

Brat Cat (1994), written by Elizabeth Hutchins and illustrated by Margaret Power, which was published two years later, was short-listed for the Australian Multicultural Children's Book Award. It portrays a character whose Korean background does pose a problem, affecting her responses, unlike the Asian origins of the twins in $\mathrm{Mr}$ Plunkett's Pool. Hutchins crafts a subtle story of a little gir! who feels insecure because she has been adopted. The illustraticns clearly show an Asian child and a non-Asian mother.

The opening lines of the text introduce the adoption theme obliquely by focusing on the acquisition of a pet: 'Most people go and get a new cat but Brat Cat got us.' Hutchins concentrates on Jae-Li's perspective by choosing a first-person narration, so she can reveal how, in the child's mind, doubt grows. The question of how they 'got' brat cat might parallel how her mother 'got' her. If one adopts a cat, or a child, what happens when the pet or child misbehaves, as Brat Cat frequently does? The refrain, 'Jae- $\mathrm{Li}$... that cat will have to go', reverberates in the girl's consciousness. The cat jumps on the kitchen table, brings fleas and a mouse, pees in a vase, but the cat also provides companionship. Jae- $\mathrm{Li}$ is too sad even for a bedtime story when her pet is sent away again. Finally, she trusts her mother enough to verbalise her fears: 'I've been as bad as Brat Cat . . Are you going to send me away too?'

Her mother responds to her fears by insisting on the question of choice. "I went all the way to Korea to get you, and you were the baby I loved the most. ... I chose you from all the others,' she said. 'And you chose me.' Jae-Li is as clever as most children, who know how to turn a parent's arguments against them. 'But Brat Cat chose us from all the other families,' I said. 'So we should keep him.' The new refrain becomes 'that cat may have to stay.'
Hutchins sensitively treats the insecurity of a child adopted, not only by a new family, but by another race in another country. The illustrations suggest the differences with which Jae-Li has to come to terms as well. Margaret Power draws a Caucasian woman who looks obviously different from her daughter. Even though Jae-Li seems settled at the story's opening, she still needs reassurance about her bonding with her mother. Her Korean origin might be secondary to the subject of adoption, but it remains to complicate her insecurity nevertheless. Perhaps that is why she needs to save the cat all the more. She craves friendship; she wants to perpetuate the cycle and to adopt, too. Her cat becomes her alter-ego, who will be loved for itself, no matter what its day-to-day behaviour might be.

Although Brat Cat works extremely well, the story does depend to some extent on the character's ethnicity. Jae$\mathrm{Li}$ 's Korean background is made explicit and the girl (as well as society) would always be aware of the physical differences between her and her mother. So while Brat Cat movingly depicts a child learning to feel secure in a new environment, it does show that ethnicity raises problems that need to be resolved.

Phil Cummins' Marty and Mei-Ling (1996; 1995), illustrated by Craig Smith, is also a picture book that attempts to interweave the subject of ethnic difference with realistic character portrayal. Marty is a boisterous primary school boy who cannot resist always telling everyone what he thinks. His type of personality, although it could cause difficulties for parents and teachers, who find themselves often embarrassed by candour, is not uncommon in Australian culture. Children are encouraged to be expressive; discretion has never been one of their virtues.

In his economical text, Cummins focuses on this driving force in Marty's energetic nature. He arrives at school, does a gorilla jump, spins on the equipment, crashes down the slide and notices right in front of his nose that one ant in a line is different. As soon as he observes this, 'he told everybody'. Cummins interweaves this refrain throughout the text. Marty then notices a new girl, MeiLing, who also is different from the norm: her name, her eyes, her hair. That perennial benchmark for underlining 
ethnicity in the schoolyard - the lunch box's contents is included, too. Because Marty keeps being Marty and focusing on Mei-Ling's dissimilarity to her peers, she feels self-conscious and decides he is 'being mean to her'.

The subject here, of course, is mutual incomprehension. Neither child recognises the other's distinct personality. Marty does not know that he hurts Mei-Ling; she does not know that he loves to observe differences. But since motivation is hidden, he nearly reduces her to tears. Cummins turns the tables in the story in order to underline this theme of unintentional, but destructive, misunderstanding. He creates a parallel situation where Marty and his parents become separated at a kite festival they decide to visit. Marty helps to tum the tables by declaring to passersby (even though they speak a language he doesn't understand) that 'My Mum and Dad are lost!' Now he is nearly reduced to tears. But Mei-Ling, who recognises him, comes to his rescue and introduces her family. They become friends, of course, and on Monday arrange to fly kites after school. The implication is that both children now know what it feels like to be bewildered in the midst of a group who share a common language and culture.

Although Cummins depicts the dynamics of the primary school classroom accurately and humorously, the tex: still emphasises the issue of ethnic difference and so perpetuates the pattern I have been tracing. The pattern has been varied, however. Marty needs to learn to be sensitive to others' feelings. In this case, it is the Asian child who displays sensitivity by taking pity on the Australian-born child. One wonders what a follow-up book would be like about Marty and Mei-Ling a year later. Would the story be the same as that of any story about two primary age children?

Morag Loh's Grandpa and Ah Gong (1995), illustrated by Xiangyi Mo), although it postulates cultural diversity as a problem, varies the approach yet again. This book is more complex because it acknowledges that another stage has been reached in our country, the result of previous waves of immigration. Mandy is the product of an interracial marriage between an Anglo mother and a Malaysian father. Her acceptance into Australian society, or her parents' relationship, is not the issue here, but the older generation's reaction to what the union signifies. It is the grandfathers who have trouble coming to terms with unfamiliar customs. Nevertheless, they are part of the extended family and their inability to communicate affects everyone.

Loh's text makes Mandy's ability to slip from one culture to another clear in parallel sequences. In the opening Mandy describes what activities she shares with her mother's father, including visiting a neighbour, Mrs Pianto (an obviously ethnic name). She shares other, equally rewarding experiences with Ah Gong, her father's father. when they travel to Malaysia. They visit his neighbour. Mr Wong, for instance. When Ah Gong comes to stay in Australia, however, the two ways of life clash.

Loh highlights the dilemma of adjusting to dissimilar cultures by focusing on Mandy's disappointment; she cannot understand why the two grandfathers she loves cannot love each other, too. The superficial things so often touted as evidence of Australia's successful multicultural blend prove not to be enough to cement relationships; for example, the existence of a LOTE (Languages Other Than English) section in the library, or the Asian food Mandy's dad and grandfather prepare. Of course the older men begin with good intentions, but their daily rhythms as well as their personalities are distinct. The question of which is the better way of living is finally voiced by the Anglo grandfather who resents having a kite that they see flying in a park criticised.

\section{'I flew kites just like that when I was a boy.' Grandpa told me. 'I made them myself.' \\ 'That's a very plain kite, 'Ah Gong said. 'Kites in Malaysia are much prettier. They look like birds and butterflies. \\ 'I suppose you think we should do things the Malaysian way!' Grandpa spoke so sharply I looked at him instead of at the kite. Ah Gong shrugged and said, 'Maybe.'}

What makes some kind of rapprochement possible, however, is in fact the product of two cultures: the child. Mandy frets because she believes that she has been the cause of dissension; consequently, she has lost the love of both grandfathers. They do not come together to pick her up at school for three days. It turns out, however, that they 
have been working in secret on a joint product: a kite they have made especially for her. In this case, kite-making crosses cultural barriers and enables the grandfathers to reconcile 'for the fun of doing things together'. Loh implies that the older men do not have to like all of the same things or to compete. Their ability to compromise is necessary, however, to resolve the plot. Grandpa and $A h$ Gong suggests that with each new generation, there will be fewer misunderstandings.

The pictorial narrative reinforces the different lifestyles of each grandfather by focusing on landscape. A tranquil urban Australian park, for example, contrasts with a busy Malaysian market scene, which includes baskets of exotic fruits and vegetables; cooking steam floats in the background. The end covers present diagrams of how to make a basic kite. This plain version contrasts with the vibrantly-coloured Malaysian butterfly kite that the grandfathers actually make in the story. Is kite making the solution to cultural conflict? We should all hope that it would be so easy. But this physical aspect of the book does not undercut the story - it only adds another dimension.

Although more developed in its treatment of ethnicity, Grandpa and Ah Gong still continues the trend of concentrating on cultural differences. Mandy's problem is one step removed, however. It is not her physical appearance or attitudes but her grandfathers' behaviour that creates dissension.

Two very recent books that also suggest that Australian society is moving to a more complex stage in the integration of migrants are both by Sally Rippin: Speak Chinese, Fang Fang and Fang Fang's Chinese New Year (1996). Their similar purpose is underlined by identical text on the opening pages, which explains that Fang Fang was born in China, though she hardly remembers it: 'Now she is Australian.'.

In Speak Chinese, Fang Fang, Rippin draws attention to ethnicity in the second double-page spread, but here a variety of ethnic backgrounds is meant to be the norm. The illustration portrays a multiracial classroom. Rippin nevertheless feels the need to make this fact explicit in the text, rather than to let readers deduce it: 'Fang Fang has lots of friends at school. Some of them were also borm in other countries.'

The subject of both Fang Fang stories does extend beyond the sometimes simplistic treatment of migrant problems in earlier books. Fang Fang's inability to feel comfortable in Australian society does not stem from her own personality or behaviour. She has integrated with a vengeance. It is her parents and their adherence to their culture (language, food, even methods of discipline) that cause difficulties. Like many migrant children, she feels embarrassed by ethnicity. In Speak Chinese, Fang Fang, for example, while on an outing with her mother she meets Amy, a school friend. Her own mother cannot speak to Amy's because she does not possess adequate English as yet. Fang Fang is disconcerted; she feels her non-Australianness holding her back, so she refuses to speak her parents' language even at home. Finally, her Chinese cousin Lily arrives and dispels some of the stereotypes. She is up to date with the latest hit songs and speaks fluent English. Suddenly, Fang Fang realises that speaking Chinese does not have to be a disability.

In Fang Fang's Chinese New Year, the central character's mother urges her to invite her friend Lisa to celebrate with them. Fang Fang is reluctant to expose herself to possible ridicule because of her background. She also worries that Lisa will be bored. Somewhat unrealistically in urban Australian society, Lisa seems to have little or no experience of Chinese food and the only fish she has eaten is from the fish shop. It is Lisa's enthusiasm for the people, food and entertainment that allows Fang Fang to feel comfortable again with her parents' culture. If her friend values that culture, then she feels she can, too.

In both Fang Fang stories the two Australian friends look like the old Anglo stereotypes - one is red-headed and the other blond - as if brown and black-haired Anglo-Saxon children do not exist. Of course the pictorial narrative emphasises that Fang Fang's appearance makes her stand out, although her behaviour, her speech and her food preferences (McDonald's hamburgers and a Coke) do not.

In these stories, then, ethnicity is still posed as a predicament for the central character, but more by extension. There is no hint that Fang Fang's appearance 
causes adverse reactions. In Grandpa and Ah Gong, Mandy had no trouble appreciating both her grandparents' cultures. Ethnic customs were only difficulties for the older generation, not for the product of an interracial marriage. In Rippin's stories, however, Fang Fang has to learn to be herself, while allowing her parents to be themselves. Valuing her Australian life does not mean devaluing her heritage. Theșe themes, however, are treated in a heavy-handed way, and so the books are not as successful as Mr Plunkett's Pool or Brat Cat, for example.

Elaine Lindsay's Mr Kwok's Kites (1994), illustrated by Helen Hunkin, is one of the few recent picture books I could find that did not pose the character's ethnic origins as a problem, which suggests that writers are beginning to move past positioning non-Anglo characters in scenarios that always involve their backgrounds. Mr Kwok is simply a person with that name, as Kim and Lee, in $\mathrm{Mr}$ Plunkett's Pool, are ordinary children.

Lindsay offers an unassuming story that concerns three children's friendship with Mr Kwok, the kite maker. He never has time to make a kite for himself to enjoy because his products are in such demand. With the best intentions, Lisa, Chris and Penny, who live next door (and who are all non-Asian), try to help him. Every time they do, however, and test fly their joint creations, one of them wishes the kite were theirs, and obliging $\mathrm{Mr}$ Kwok lets them have it. Lisa receives the leopard, Chris the crocodile and Penny the peacock. Finally the three children and $\mathrm{Mr}$ Kwok finish a kite that $\mathrm{Mr}$ Kwok can keep for himself: a rainbow. Since he is master of kites and colours, that seems appropriate.

Hunkin employs a clever strategy in her pictorial narrative. She executes the first illustration in black pencil. Gradually, colour creeps into the text as the kites are completed. Perhaps the subtext is that friendship and generosity bring colour to all the lives in the story. The ability to construct magnificent kites certainly is an Asian tradition, but nothing explicit is made of that fact here. $\mathrm{Mr}$ Kwok is simply an excellent kite maker. Still, another subtext attributes a significance to kites similar to that in other picture books I have discussed. Kites function as a symbol of both the artistic side of Asian culture and of a cross-cultural play activity in which all ages can share.
The landscapes in Mr Kwok's Kites seem to be intentionally generai; they could be located in an outer suburb or town in most states in Australia. Mr Kwok and the children live in the kind of turn of the century cottages found so frequently (as John Stephens argued). They do construct a kind of social setting that is essentially conservative' (Stephens 1994, p.70), because it recalls the past. But Mr Kwok has been able to move into this environment and to make himself at home, suggesting that the architectural past has not had a constraining influence on the multicultural present. The four friends test fly the kites on a hill, on a cliff top, on a tower (a wooden one like those found in adventure playgrounds) and in the sand dunes. Because the environment is not specifically urban or rural, it becomes, in a sense. more national. The various backdrops for the kite flying suggest that the activities that take place there, and the people involved, are ordinary. There is no need to call attention to the ethnic origins of the children or Mr Kwok, or to explain anything about the kind of kites they make.

The final book that this paper discusses does not present ethnic origins as a problem, but it does treat them as a curiosity, so it has not extended the use of non-Anglo protagonists. Jenni Overend's Princess Grandma (1994) illustrated by Naomi C Lewis, won the 1995 Multicultural Children's Award for a picture book - the last one to be given be fore the present government abolished the Office of Multicultural Affairs. This is a reflective story, supported appropriately by Lewis' watercolour and coloured pencil drawings in muted pastel tones. They complement the text's pace and occasional lyricism. which sometimes verges on cliche. Occasionally there are rectangular pictures, with borders that resemble those on woven mats, inset into the larger illustrations. These give the impression of vignettes out of the lives of the two central characters.

Princess Grandma is narrated by a blond girl who lives next door to a woman whom 'they said was a Fijian princess'. Like everyone else, however, the girl calls her Grandma. Overend's wordy tale builds up a picture of the relationship of the two. Basically, the old woman shares her cultural heritage with her neighbour, who is fascinated by the fragrant curries and tales of the Turtle Calling and the Shark God, tales which readers do not hear. (They 
absorb' only snippets and have to trust the child's enthusiasm.) She also likes the children who visit: "I would try to unwind their tight black curls to see how far down their backs they would reach.' In this depiction of Fijian culture, even the children are picturesque. Mostly Grandma and the girl share domestic occupations. For instance, they spend time in the garden, where Grandma grows her own types of vegetables: yams, taros, sweet potatoes. Lewis draws the young Anglo girl with a basket full of flowers and leafy vegetables, arm and arm with a little Fijian girl.

The sentiments are admirable, Lewis' illustrations well executed, but Overend does not deliver much story. The climax, if it can be called one, happens when the young neighbour comes to visit on a Sunday evening and finds 'someone with a halo of tight black curls around her face'. Grandma has died and been taken back to Fiji, presumably, to be buried 'on a hill that overlooked a white beach by a turquoise sea'. She has left a woven mat for the girl, who lies on it sometimes on hot nights to resurrect dreams of Grandma and her native land.

Princess Grandma demonstrates respect for Fijian culture and focuses on how the young girl's life is enriched by knowing Grandma. In fact, the back cover blurb states that 'her stories ... would change the little girl forever'. Perhaps they do, but readers cannot truly judge, because they do not share in enough of the stories or in the girl's inner thoughts. Aside from Mr Kwok, Grandma is the only other adult central character in the books I have discussed who does not seem to feel out of place in Australia. On the other hand, she seems to live a life similar to that she would have lived in Fiji, separated in a kind of time capsule from the ordinary existence of the girl, who is fascinated because everything about Grandma is so different from what she knows. The difference here is an attraction, not a problem. Readers might not want to see Grandma assimilated so that she loses her distinctiveness, but even her removal for burial offshore suggests that her ties to Australia were tenuous. Princess Grandma functions less like fiction than like an information book, where the food, clothing, houses and myths of another country are reported. Children would learn about Fijian culture, but not become emotionally involved with either character. Overend's book, then, does not extend the treatment of non-Anglo protagonists in imaginative literature.

\section{The New Fringe Dweilers}

The appearance of non-Anglo children or adults as picture book protagonists has not increased to a substantial degree in recent years. The ones who do appear still grapple with their ethnicity or are defined by it, as Princess Grandma is. Ethnic characters are visible in depictions of schoolyard or shop, but they are not central, like Kim and Lee in MrPlunkett's Pool. All of the books discussed above have met the guidelines for consideration in the former Australian Multicultural Children's Literature Award. But is that all we can ask on a literary as well as on a social level? Has there been a lack of any further treatment of ethnic characters in vital and believable stories because there are not more authors and illustrators of non-Anglo origins working in the field of children's picture books?

Donna Rawlins seems to think that this is part of the problem; she awaits 'new creators from different cultures' (1994, p.246), as reviewers have been awaiting a Greek or Vietnamese Melina Marchetta. But does this mean that those from the mainstream continue to be blind to ethric people? Do they fail to see ethnic children as candidates for their stories, having all the usual problems of growing up? I do not think that there are easy answers to these questions. I can only judge by the picture books that have been published to date. Of course, as Donna Rawlins maintains, ethnic characters do not necessarily have to be central for us to assert that the literature in which they appear accurately depicts Australian culture: 'There are many ways to be inclusive of other cultures in one's pictures' (1994, p.248), for example. She counsels illustrators to open their eyes 'to draw the here... to draw the now' (1994, p.249).

This peripheral inclusion, however, can lead to marginalisation, to stereotyping or to the type of tokenism typical of educational series, which make migrants sometimes seem like the new fringe dwellers. Full inclusion of them must supersede the balanced mix of skin tone and facial characteristics in the classroom. It is 
too easy to nod pictorially at distinctiveness, but to leave it out of the principal narrative. Ethnic characters do not seem, at least in recent picture books, to be treated on a wide scale as Australians who have problems that are not connected with their origins.

\section{NOTE}

Other books that I have not been able to consider are those that retell myths, traditional tales or stories from nonAustralian cultures. Junko Morimoto's Kojuro and the Bears or The Night Hawk Star, Selina Li Duke and Stanley Wong's In The Year of the Tiger and Wendy Lohse's Is It True Grandfather? fall into this category. The effect of these books is manifoid, but they do not deal with ethnicity per se in Australian society. I have also not considered trade picture books that seem to be primarily for educative purposes, such as Libby Gleeson and Penny Azar's Mum Goes to Work.

\section{REFERENCES}

Jupp, James (1996) Understanding Australian Multiculturalism. Canberra, Australian Government Publishing Service.

Macquarie Dictionary (1981) St Leonard's, NSW, Macquarie Library.

Rawlins, Donna. (1994) The environment of the child', in B. Alderman \& P. Clayton (eds) Creative Connections: Writing, Mlustrating and Publishing Children's Books in Australia. Papers of the Canberra Children's Book Council Seminars 1987-1993. Melbourne, DW Thorpe, pp.241-253.

Saxby, Maurice (1993) The Proof of the Puddin': Australian Children's Literature 1970-1990. Sydney, Ashton Scholastic.

Starke, Ruth (1995) 'What is a multicultural book?' Viewpoint: On Books for Young Adults, 3. No 1 (Autumn): 22-24.

Stephens, John (1994) 'Illustrating the landscape in Australian children's picture books', in Wendy Parsons \& Robert Goodwin (eds) Landscape and ldentity: Perspectives from Australia. Proceedings of the 1994 Conference of the Centre for Children's Literature, University of South Australia. Adelaide. Auslib Press, pp.69-83.

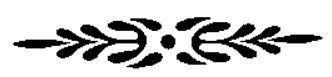

\section{ACKNOWLEDGEMENT}

This article was originally published in Maureen Nimon (ed) (1997) Old Neighbours New Visions: Selected Papers from the First Conference of the Australasian Children's Literature Association for Research, Centre for Children's Literature, University of South Australia.

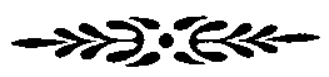

\section{BIOGRAPHICAL NOTE}

Dr Jeri Kroll is a Senior Lecturer in the School of English and Drama at Flinders University. She is the convenor of the creative writing program and also the author of several books of poetry and fiction for adults and fiction. 